\title{
"It's helpful to get the time and opportunity to discuss drug treatment; that's what I think is the most important thing."-A qualitative study on prescribing education in junior physicians
}

\author{
Johan Lönnbro ${ }^{1,2}$ (D) Susanna M. Wallerstedt ${ }^{1,3}$ (D)
}

Received: 25 April 2019 / Accepted: 13 September 2019 / Published online: 22 November 2019

(C) The Author(s) 2019

\begin{abstract}
Background As prescribing skills are a prerequisite for rational use of medicines, and education and training are important in acquiring these skills, we aimed to explore what aspects junior physicians find important when being taught the art of prescribing. Methods Written feedback from 34 interns after participating in an educational session as part of a randomized controlled study at a university hospital formed the qualitative data in this study. Manifest content analysis was performed, guided by the research question "Educating junior physicians in the art of prescribing: what aspects do they find important?" Meaning units were extracted and categorized, and emergent themes were identified.

Results Five themes emerged. The first, clinical relevance, was exemplified by the categories valuable for health care; perceived relevance for one's own work; and translating theory into practice while the second, applicable content, included categories such as clinical advice; practical tips on using the electronic medical record system; and tools that facilitate. The third and fourth themes, reality-based teaching and creative discussions, were exemplified by the categories patient cases and feedback; and discussion-based teaching; wide-ranging discussions and a permissive and open atmosphere, respectively. In the last theme, effective structure, we identified the categories clear structure; small group teaching; allocated time for discussion; wellorganized administration; and home assignment for practice.

Conclusion Creative discussions, effectively structured in small group sessions, with clinically relevant, reality-based content built on case studies and feedback, are aspects which junior physicians find important when educated in the art of prescribing.
\end{abstract}

Key words Education $\cdot$ Internship $\cdot$ Prescribing $\cdot$ Qualitative $\cdot$ Teaching

\section{Background}

Drug treatment is a key element of modern health care. Worldwide, the increasing number of patients with treatable, often multiple, diseases puts great demands on physicians' prescribing skills. Indeed, the safe and rational use of medicines is essential to maximize the benefits and minimize the harms of pharmacotherapy. However, the complex art of

Johan Lönnbro

johan.lonnbro@gu.se

1 Department of Pharmacology, Sahlgrenska Academy, University of Gothenburg, SE-413 90, Gothenburg, Sweden

2 Department of Medicine, Sahlgrenska University Hospital, SE-413 45 Gothenburg, Sweden

3 HTA Centre, Sahlgrenska University Hospital, SE-413 45 Gothenburg, Sweden prescribing, taking into account the unique circumstances of each patient, takes years to master, requiring pharmacological knowledge in combination with diagnostic competence. The process of acquiring these skills starts in medical school [1] and continues throughout the physician's professional life.

The need for improvements regarding junior physicians' prescribing skills has been previously highlighted [2-5]. Indeed, medical schools have been reported not to prepare their students sufficiently for this professional task $[6,7]$. Several educational efforts have been evaluated for improved prescribing practices $[8,9]$. However, these interventions are likely to be designed by the education providers, and, as far as we are aware, scientific evidence regarding the needs and wishes of the recipients is largely lacking.

Knowledge on aspects perceived as important by junior physicians targeted in educational efforts could be valuable in the continuous endeavour to improve the prescribing skills of physicians [10]. Indeed, few physicians consider current 
teaching sessions effective [11]. Therefore, this study was performed to explore what junior physicians find important when being taught the art of prescribing, using evaluation texts provided after an educational intervention.

\section{Methods}

In this qualitative study, we performed a manifest content analysis [12] guided by the research question "Educating junior physicians in the art of prescribing: what aspects do they find important?" The material consisted of written feedback provided by interns after participating in two 3 -h seminars with collegial discussions on pharmacotherapy. About 10 min was allowed at the end of the second seminar for the participants to provide anonymous free-text replies to the questions "What was helpful about the seminars?" and "What could be improved?" The participants were not aware that their responses were to be analyzed qualitatively.

The seminars were part of a randomized controlled study performed in Sahlgrenska University Hospital, Gothenburg, Sweden, consecutively recruiting interns between 2014 and 2016 and described elsewhere [13]. Internship in Sweden means post-graduate vocational training for 1.5 years to obtain a license to practice medicine and continue with specialization. It includes working as a physician in internal medicine, surgery, psychiatry, and primary care, prescribing medicines in daily patient care. Summarized, 98 interns were invited to participate, 24 of whom could not be reached or did not respond to the invitation, and five of whom declined participation. In total, 69 interns were randomized, eight of whom did not attend the seminars (intervention group) and four of whom did not answer the questionnaires (control group); thus, 57 participants completed the study. Thirty-five interns participated in the second seminar either before (intervention group) or after (control group) collection of outcome data. All but one of the participants contributed with data to the present study ( $n$ $=34$ ). The participants' median age was 30 years (range $25-$ 48 years); $57 \%$ were female and $26 \%$ were conducting research as part of their internship, their clinical work being prolonged correspondingly. The educational intervention has been described in detail elsewhere [13].

The qualitative analysis was performed by the two authors, from the perspective of being a physician specialized in clinical pharmacology and a professor in pharmacotherapy (S.M.W.), and a physician specialized in internal medicine (J.L.). Both researchers have broad experience in teaching medical students and junior physicians within pharmacotherapy, as this is a major task for clinical pharmacologists [14-16] and an important part of the daily work of internists working at a university hospital.

In the first step of the analysis, we independently identified and extracted meaning units concerning the overall research question "Educating junior physicians in the art of prescribing: what aspects do they find important?" Answers to the "What was helpful" question were referred to as "appreciate statements (A)" and to the "What could be improved" question as "improvement statements (I)." Next, we discussed all identified meaning units and reached consensus regarding the extractions. At the end of the process of identifying meaning units, similar codes kept reappearing, while no new codes emerged, indicating that saturation had been reached. Thereafter, we performed a data-driven inductive thematic analysis without any predetermined categories or themes. This involved repeatedly sorting the various units into categories until consensus was reached. Finally, we identified emergent themes, each one of which was a thread of an underlying meaning at an interpretative level [12]. Throughout the process of analysis, any disagreements were resolved through discussion. NVivo 12 Pro (QSR International, Melbourne, Australia) was used for data management.

\section{Results}

Five themes emerged from the content analysis: clinical relevance; applicable content; reality-based teaching; creative discussions; and effective structure. The themes and the associated categories are presented in Fig. 1. Below, themes and categories are summarized and illustrated by representative quotes from the interns.

\section{Theme I: Clinical relevance}

Three categories formed this theme: perceived relevance for one's own work; valuable for health care; and translating theory into practice. The first category concerned the importance of the provided education in general. The interns felt that education in pharmacotherapy and training in prescribing were needed for their clinical work and were not sufficiently included elsewhere in their education, and that medication reviews are useful. Example quotes in the category perceived relevance for one's own work were:

\footnotetext{
"Important information we didn't get enough of before ..." (appreciate statement (A): respondent 30)

"Important knowledge to manage drug treatment in our daily work" (A: respondent 17)

"Should be offered to all interns at the beginning of internship." (A: respondent 24)
}

The categories valuable for health care and translating theory into practice included quotes such as: 


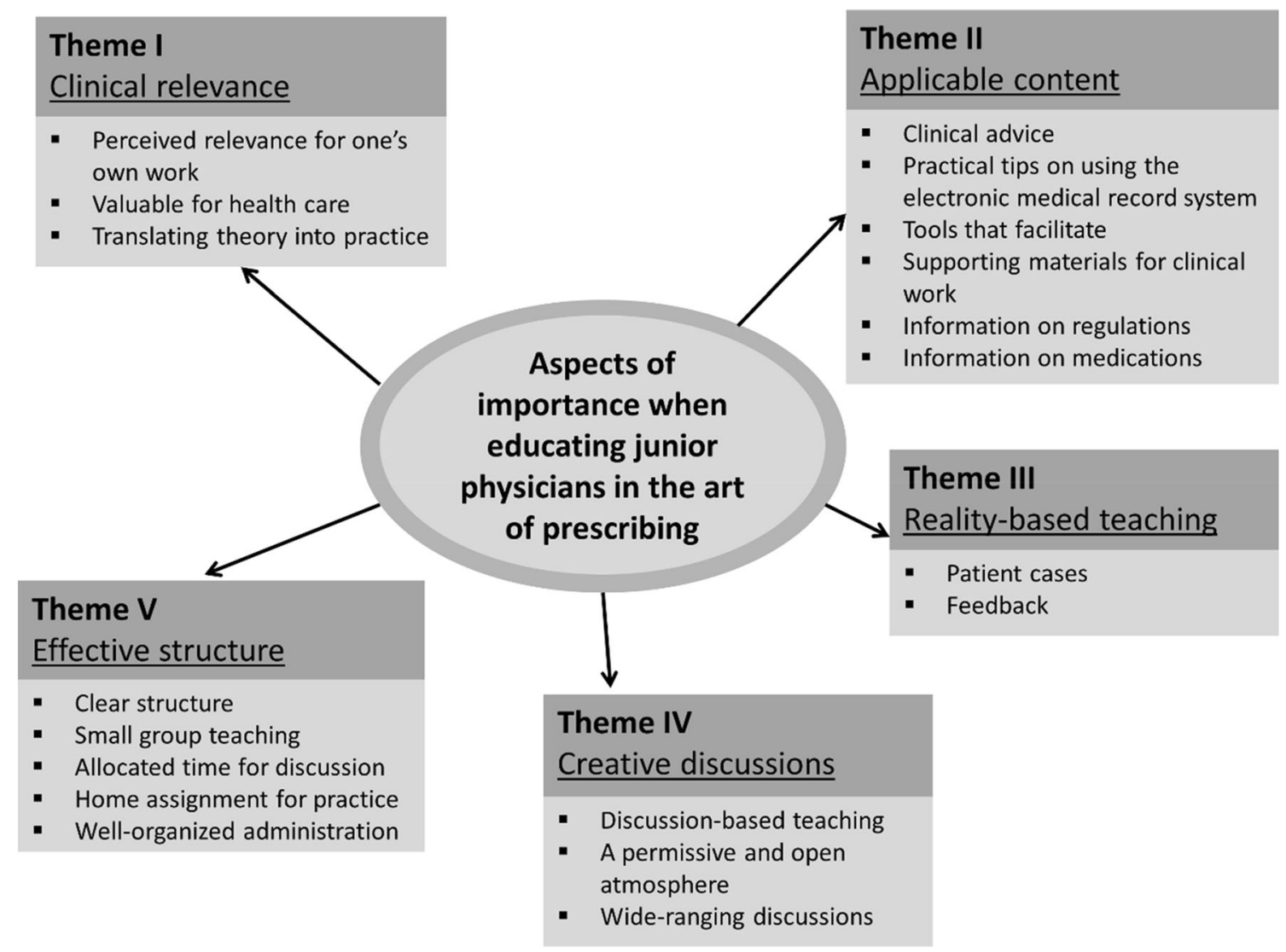

Fig. 1 Themes and categories that emerged from the meaning units

\begin{abstract}
"Helpful discussions overall, on why documentation is important and how it facilitates our work and is good for the patients" (A: respondent 15)

"If you want a change in behavior it's essential that consultants on the wards are also committed [to change]." (A: respondent 27)
\end{abstract}

\section{Theme II: Applicable content}

This theme concerned the interns' thoughts on the contents of the educational intervention. Being the most extensive of the five themes when it comes to the number of meaning units identified, this theme comprised the categories clinical advice; practical tips on using the electronic medical record system; and tools that facilitate; as well as supporting materials for clinical work; information on regulations; and information on medications.

Under the categories clinical advice and practical tips on using the electronic medical record system, the interns described that they appreciated a hands-on approach, as illustrated by the following quotes:
"Hands-on tips which have already helped me in my clinical work" (A: respondent 30)

"Tips on how best to use the prescribing module in the medical record system" (A: respondent 7)

"Nice tips on keyboard shortcuts!" (A: respondent 3)

In the categories tools that facilitate and supporting materials for clinical work, the interns described the guidance through the available decision support tools as valuable.

"Practical tips on how to find out medications prescribed for the patient, and computerized support systems to evaluate treatment" (A: respondent 11)

"The laminated quick reference to drugs to avoid in the elderly - many want to copy it!" (A: respondent 23)

The quotes in the final two categories within this theme, information on regulations and information on medications, reflected that the interns thought background know-how important. This referred to the performance of medication reviews, for instance; it also referred to information on specific medications, including drug interactions and side effects, 
medications to avoid in older patients, and other general pharmacotherapeutic information:

"Templates, examples, and a quick reference guide on what medication reviews and medication discharge summaries can/should look like" (A: respondent 31)

"Always helpful to review common medications and aspects which can be overlooked." (A: respondent 12)

\section{Theme III: Reality-based teaching}

This theme consisted of two categories: patient cases and feedback. The junior physicians appreciated that the educational intervention was built around authentic and fictive patient cases, and that there was time both for reflection and to receive, as well as give, feedback on their own and others' work, as illustrated by the quotes:

"Focus on patient cases" (A: respondent 10)

"Nice to get the opportunity to discuss patients in whose case we have been involved." (A: respondent 4)

"You could consider distributing examples of good and poor medication discharge summaries to enable comparisons and thereby improvements of participants' work." (I: respondent 1)

\section{Theme IV: Creative discussions}

This theme consisted of three categories: discussion-based teaching; a permissive and open atmosphere; and wideranging discussions. In all three, the interns emphasized the importance of an open climate for informed discussions.

That the teaching was discussion-based was highly appreciated, eliciting eleven quotes such as:

"Interesting discussions!" (A: respondent 25)

"A great deal of discussion" (A: respondent 13)

The category a permissive and open atmosphere included quotes such as:

"Everyone was listened to and was able to raise issues."

(A: respondent 20)

"Open climate, accepting attitudes" (A: respondent 33)

In the third category, wide-ranging discussions, the quotes illustrated the importance of the in-depth expertise of the tutors:
"Knowledgeable tutors that could give examples" (A: respondent 33)

“... discuss some things more in depth following questions from the participants" (A: respondent 7)

\section{Theme V: Effective structure}

The final theme contained five categories: clear structure, small group teaching, allocated time for discussion, home assignment for practice, and well-organized administration. The interns described factors of importance when it came to how the intervention was structured and administered, including the small group size and the interactive teaching, with participants encouraged to engage in discussion.

The quotes in the category clear structure focused on the importance of a structured review of essential aspects in prescribing and of allowing enough time to manage the home assignment in between sessions:

\footnotetext{
"A pedagogic and systematic review on how to perform medication reviews" (A: respondent 11)

"More space between the seminars would have been preferable, to allow time for gathering cases." (I: respondent 31)
}

The quotes in the categories small group teaching and allocated time for discussion showed that the small group setting allowed everyone to be active and that the structure of the seminars included time for questions and discussions:

"That we were only a few (participants) $\ldots$ better discussions, dialogue." (A: respondent 18)

"Room for discussions and questions" (A: respondent 6)

"It's helpful to get the time and opportunity to discuss drug treatment; that's what I think is the most important thing." (A: respondent 34)

The category home assignment for practice focused on getting participants to practice their new skills and apply their new knowledge and thereafter have the opportunity to receive feedback:

\footnotetext{
"An assignment to practice medication reviews increases the chance that we will continue this task." (A: respondent 12)

"It was tremendous to have an assignment and review it during the second seminar." (A: respondent 21)
} 
Finally, the interns commented that the intervention had been well organized, although they wished that they had been given more options on when to participate. The scheduling had been appropriate, and they had even been offered a cup of coffee and a sandwich, which had made a favorable impression.

\section{Discussion}

This qualitative study shows that creative discussions, effectively structured with clinically relevant and applicable, reality-based content, are the key to educating junior physicians in the art of prescribing. Although these findings may not surprise experienced teachers, they do illustrate that exploring the subject and having the main themes outlined may facilitate the design of post-graduate courses on rational and safe use of medicines for physicians worldwide. Indeed, negative patient effects cannot be excluded when physicians with little experience begin prescribing [17].

Our finding that creative discussions based on patient cases provide a desirable format of education supports the design of previous efforts to increase clinical learning of interns [18]. Indeed, active learning has been shown favorable among students [19], a finding which may also apply to post-graduate training. The small group format may facilitate discussions, and interaction between knowledgeable tutors and participants has been shown to increase the comfort of the group and their performance regarding the topics focused on $[13,18,20]$. Interestingly, a recent educational effort using small-group educational workshops with peers increased evidence-based practice among the participating health professionals [21]. In some settings, small group teaching may be hard to achieve because of scarcity of tutors. Team-based learning may be worth testing in such cases. This teaching structure implies that students learn from each other; everyone is required to be theoretically prepared for small group peer discussions regarding complex, real-life problems [22].

Clinical relevance and applicable content were important to the interns. In this context, the seniority of the tutors may be important. Indeed, the complexity of prescribing takes time to master, including determining priorities in a time-pressured medical environment. However, positive experiences from peer-led orientation for new interns have been described elsewhere [20], suggesting that time for interaction with colleagues may add value, irrespective of seniority.

As taking care of patients is the primary, and sometimes challenging, task for the physician, a permissive and open atmosphere with the opportunity to discuss reality-based experiences and thoughts was found to be important in the educational sessions. Indeed, although high-quality evidence is lacking regarding the effects of feedback [23, 24], allowing time for such interaction has been shown to be favorable for job performance [25]. Further, occupational distress, which has been reported to be relatively frequent among junior physicians [26], may be alleviated through interactive feedback sessions.

Although many participants were relatively young and, therefore, many were well acquainted with information technology, the interns wanted guidance regarding the electronic medical record system, including electronic prescribing, as well as available decision support tools. This finding emphasizes the importance of providing practical instructions early during post-graduate training. For efficient work, the physician needs to be well acquainted with the local electronic prescribing system; such systems may differ between hospitals/care centers. Indeed, orientation in job-related tasks has been shown to boost intern confidence [27], and the need for training in computer order entry has previously been described [28]. In fact, electronic health records may add to a physician's daily frustration; in a study from the USA, about half of the included licensed physicians reported that electronic records can hinder the clinical workflow [29].

The interns appreciated the clear structure of the intervention. This indicates that tutors need to be allowed sufficient time for planning education sessions. However, the easy-to-do efforts must not be ignored; the interns also appreciated being introduced to practical tools and provided with supporting materials. Likewise, the usefulness of intern manuals has previously been acknowledged $[20,28]$.

\section{Strengths and limitations}

The most important strength of this study is that it provides a comprehensive picture on aspects perceived as important, from the interns' perspective, in facilitating learning of the art of prescribing. To the best of our knowledge, such information is lacking in the literature.

Another strength is the richness of the material. Obtaining input from 34 interns of both sexes and various ages, and with/ without research experience, was sufficient to reach saturation in this study. However, as all participants were interns at a university hospital and had chosen to take part in an educational intervention study, we cannot exclude that some aspects, applicable in other settings, may remain unexplored. Also, having participated in an educational intervention, the interns could have been more prone to comment on aspects just experienced.

\section{Conclusion}

Prescribing is a central task for clinical pharmacologists and internists. Exploring key aspects of training junior physicians in the art of prescribing, this study provides valuable information on teaching within this field. Focusing on effectively 
structured small group sessions with creative and clinically relevant, patient-based discussions, including feedback, may constitute an approach, satisfying education-related preferences of interns.

Acknowledgements Open access funding provided by University of Gothenburg. We are grateful to all interns who participated in the study. We also want to thank the former internship heads of Sahlgrenska University Hospital, Caterina Finizia and Paulin Andréll, who allowed us to perform the original study within the interns' working hours.

Contribution of authors S.M.W. conceived the study and J.L. and S.M.W. designed it. J.L. and S.M.W. identified the meaning units and performed the inductive thematic analysis. Both authors drafted the manuscript and revised it for intellectual content, and both are guarantors of this work.

Funding This study was supported by the Health and Medical Care Committee of Region Västra Götaland (grant numbers VGFOUREG392071, VGFOUREG-476621). The funding source did not influence the design or conduct of the study, nor the collection, management, analysis and interpretation of the data, or preparation, review and approval of the manuscript.

\section{Compliance with ethical standards}

Ethical approval The study complies with the Declaration of Helsinki, and ethics approval was obtained from the Regional Ethical Review Board in Gothenburg (ID: 344-14). All participants provided informed consent in writing before inclusion in the randomized controlled study. In an amendment to the Regional Ethical Review Board, approval was obtained to perform this study without additional informed consent.

Conflict of interest The authors declare that they have no conflict of interest.

Open Access This article is distributed under the terms of the Creative Commons Attribution 4.0 International License (http:// creativecommons.org/licenses/by/4.0/), which permits unrestricted use, distribution, and reproduction in any medium, provided you give appropriate credit to the original author(s) and the source, provide a link to the Creative Commons license, and indicate if changes were made.

\section{References}

1. Eriksson AL, Wallerstedt SM (2018) Developing confidence in basic prescribing skills during medical school: a longitudinal questionnaire study investigating the effects of a modified clinical pharmacology course. Eur J Clin Pharmacol 74(10):1343-1349. https:// doi.org/10.1007/s00228-018-2508-3

2. Harding S, Britten N, Bristow D (2010) The performance of junior doctors in applying clinical pharmacology knowledge and prescribing skills to standardized clinical cases. Br J Clin Pharmacol 69(6): 598-606. https://doi.org/10.1111/j.1365-2125.2010.03645.x

3. Dornan T, Ashcroft D, Heathfield H, Lewis P, Miles J, Taylor D et al. (2009) An in depth investigation into causes of prescribing errors by foundation trainees in relation to their medical education: EQUIP study. Final report or the GMC. [cited 2019 July 3].
Available from: http://www.gmc-uk.org/FINAL_Report prevalence_and_causes_of_prescribing_errors.pdf_28935150.pdf

4. Ryan C, Ross S, Davey P, Duncan EM, Francis JJ, Fielding S, Johnston M, Ker J, Lee AJ, MacLeod MJ, Maxwell S, McKay GA, McLay JS, Webb DJ, Bond C (2014) Prevalence and causes of prescribing errors: the PRescribing Outcomes for Trainee Doctors Engaged in Clinical Training (PROTECT) study. PLoS One 9(1):e79802. https://doi.org/10.1371/journal.pone.0079802

5. Reynolds M, Jheeta S, Benn J, Sanghera I, Jacklin A, Ingle D, Franklin BD (2017) Improving feedback on junior doctors' prescribing errors: mixed-methods evaluation of a quality improvement project. BMJ Qual Saf 26(3):240-247. https://doi.org/10. 1136/bmjqs-2015-004717

6. Brinkman DJ, Tichelaar J, Okorie M, Bissell L, Christiaens T, Likic R, Mačìlaitis R, Costa J, Sanz EJ, Tamba BI, Maxwell SR, Richir $\mathrm{MC}$, van Agtmael M, for the Education Working Group of the European Association for Clinical Pharmacology and Therapeutics (EACPT) (2017) Pharmacology and therapeutics education in the European Union needs harmonization and modernization: a cross-sectional survey among 185 medical schools in 27 countries. Clin Pharmacol Ther 102(5):815-822. https://doi.org/10. 1002/cpt.682

7. Brinkman DJ, Tichelaar J, Schutte T, Benemei S, Böttiger Y, Chamontin B, Christiaens T, Likic R, Ma iulaitis R, Marandi T, Monteiro EC, Papaioannidou P, Pers YM, Pontes C, Raskovic A, Regenthal R, Sanz EJ, Tamba BI, Wilson K, Vries TP, Richir MC, Agtmael MA, on behalf of the Working Group Research on CPT Education of the European Association for Clinical Pharmacology and Therapeutics (EACPT) (2017) Essential competencies in prescribing: a first European cross-sectional study among 895 finalyear medical students. Clin Pharmacol Ther 101(2):281-289. https://doi.org/10.1002/cpt.521

8. Forsetlund L, Bjorndal A, Rashidian A, Jamtvedt G, O'Brien MA, Wolf $\mathrm{F}$ et al. (2009) Continuing education meetings and workshops: effects on professional practice and health care outcomes. Cochrane Database Syst Rev (2):Cd003030. doi:https://doi.org/10.1002/ 14651858.CD003030.pub2

9. O’Brien MA, Rogers S, Jamtvedt G, Oxman AD, Odgaard-Jensen J, Kristoffersen DT et al. (2007) Educational outreach visits: effects on professional practice and health care outcomes. Cochrane Database Syst Rev (4):Cd000409. doi:https://doi.org/10.1002/ 14651858.CD000409.pub2

10. Brinkman DJ, Tichelaar J, Mokkink LB, Christiaens T, Likic R, Maciulaitis R, Costa J, Sanz EJ, Maxwell SR, Richir MC, van Agtmael MA, the Education Working Group of the European Association for Clinical Pharmacology and Therapeutics (EACPT) and its affiliated Network of Teachers in Pharmacotherapy (NOTIP) (2018) Key learning outcomes for clinical pharmacology and therapeutics education in Europe: a modified Delphi Study. Clin Pharmacol Ther 104(2):317-325. https:// doi.org/10.1002/cpt.962

11. Gharbi M, Moore LS, Castro-Sanchez E, Spanoudaki E, Grady C, Holmes AH et al (2016) A needs assessment study for optimising prescribing practice in secondary care junior doctors: the Antibiotic Prescribing Education among Doctors (APED). BMC Infect Dis 16(1):456. https://doi.org/10.1186/s12879-016-1800-z

12. Graneheim UH, Lundman B (2004) Qualitative content analysis in nursing research: concepts, procedures and measures to achieve trustworthiness. Nurse Educ Today 24(2):105-112. https://doi.org/ 10.1016/j.nedt.2003.10.001

13. Lönnbro J, Nylen K, Wallerstedt SM (2019) Developing professional confidence in the art of prescribing-a randomized controlled study on structured collegial discussions during internship. Eur J Clin Pharmacol 75:687-696. https://doi.org/10.1007/s00228-01802619-4 
14. Birkett D, Brosen K, Cascorbi I, Gustafsson LL, Maxwell S, Rago $\mathrm{L}$ et al (2010) Clinical pharmacology in research, teaching and health care: considerations by IUPHAR, the International Union of Basic and Clinical Pharmacology. Basic Clin Pharmacol Toxicol 107(1):531-559. https://doi.org/10.1111/j.1742-7843. 2010.00602.x

15. Wallerstedt SM, Rosenborg S (2013) Characteristics and apprehensions of clinical pharmacologists in Swedish healthcare-a questionnaire study. Eur J Clin Pharmacol 69(Suppl 1):95-99. https://doi. org/10.1007/s00228-013-1485-9

16. Aronson JK (2012) What do clinical pharmacologists do? A questionnaire survey of senior UK clinical pharmacologists. Br J Clin Pharmacol 73(2):161-169. https://doi.org/10.1111/j.1365-2125. 2011.04079.x

17. Young JQ, Ranji SR, Wachter RM, Lee CM, Niehaus B, Auerbach AD (2011) "July effect": impact of the academic year-end changeover on patient outcomes: a systematic review. Ann Intern Med 155(5):309-315. https://doi.org/10.7326/0003-4819-155-5201109060-00354

18. Gillen JR, Farineau DW, Lau CL, Williams MD, Marzani-Nissen GR (2015) Observations: utilizing an interactive case-based format for intern orientation. J Grad Med Educ 7(2):301-302. https://doi. org/10.4300/jgme-d-14-00744.1

19. Freeman S, Eddy SL, McDonough M, Smith MK, Okoroafor N, Jordt H, Wenderoth MP (2014) Active learning increases student performance in science, engineering, and mathematics. Proc Natl Acad Sci U S A 111(23):8410-8415. https://doi.org/10.1073/pnas. 1319030111

20. Otokiti A, Sideeg A, Ward P, Dongol M, Osman M, Rahaman O, Abid S (2018) A quality improvement intervention to enhance performance and perceived confidence of new internal medicine residents. J Community Hosp Intern Med Perspect 8(4):182-186. https://doi.org/10.1080/20009666.2018.1487244

21. Mickan S, Hilder J, Wenke R, Thomas R (2019) The impact of a small-group educational intervention for allied health professionals to enhance evidence-based practice: mixed methods evaluation. BMC Med Educ 19(1):131. https://doi.org/10.1186/s12909-019$1567-1$
22. Burgess AW, McGregor DM, Mellis CM (2014) Applying established guidelines to team-based learning programs in medical schools: a systematic review. Acad Med 89(4):678-688. https://doi. org/10.1097/acm.0000000000000162

23. Bing-You R, Hayes V, Varaklis K, Trowbridge R, Kemp H, McKelvy D (2017) Feedback for learners in medical education: What is known? A scoping review. Acad Med 92(9):1346-1354. https://doi.org/10.1097/acm.0000000000001578

24. Hayes V, Bing-You R, Varaklis K, Trowbridge R, Kemp H, McKelvy D (2017) Is feedback to medical learners associated with characteristics of improved patient care? Perspect Med Educ 6(5): 319-324. https://doi.org/10.1007/s40037-017-0375-8

25. Arundel C, Logan J, Ayana R, Gannuscio J, Kerns J, Swenson R (2015) Safe medication reconciliation: an intervention to improve residents' medication reconciliation skills. J Grad Med Educ 7(3): 407-411. https://doi.org/10.4300/jgme-d-14-00565.1

26. Bernburg M, Vitzthum K, Groneberg DA, Mache S (2016) Physicians' occupational stress, depressive symptoms and work ability in relation to their working environment: a cross-sectional study of differences among medical residents with various specialties working in German hospitals. BMJ Open 6(6):e011369. https:// doi.org/10.1136/bmjopen-2016-011369

27. Antonoff MB, Swanson JA, Acton RD, Chipman JG, Maddaus MA, Schmitz CC, D'Cunha J (2010) Improving surgery intern confidence through the implementation of expanded orientation sessions. Surgery 148(2):181-186. https://doi.org/10.1016/j.surg. 2010.04.006

28. Wright M, Mankey CG, Miller BW (2013) Improving upon the 'July effect': a collaborative, interdisciplinary orientation for internal medicine interns. Med Educ Online 18:23249. https://doi.org/ 10.3402/meo.v18i0.23249

29. Gardner RL, Cooper E, Haskell J, Harris DA, Poplau S, Kroth PJ, Linzer M (2019) Physician stress and burnout: the impact of health information technology. J Am Med Inform Assoc 26(2):106-114. https://doi.org/10.1093/jamia/ocy 145

Publisher's note Springer Nature remains neutral with regard to jurisdictional claims in published maps and institutional affiliations. 